\title{
Pro-growth, pro-poor: Is there a tradeoff?
}

\author{
J. Humberto Lopez ${ }^{*}$ \\ The World Bank (PRMPR)
}

\begin{abstract}
Is a pro-growth strategy always the best pro-poor strategy? To address this issue, this paper provides an empirical evaluation of the impact of a series of pro-growth policies on inequality and headcount poverty. We rely on a large macroeconomic data set and estimate dynamic panel models that allow us to differentiate between the short- and longrun impacts of the policies under consideration on growth, inequality and poverty. Our findings indicate that regardless of their impact on inequality, all the pro-growth policies we consider lead to lower poverty levels in the long run. However, we also find evidence indicating that some of these policies may lead to higher inequality and, under plausible assumptions for the distribution of income, to higher poverty levels in the short run. These findings would justify the adoption of a pro-growth policy package as the center of any poverty reduction strategy together with pro-poor measures that complement such a package by offsetting potential short-run increases in poverty.
\end{abstract}

World Bank Policy Research Working Paper 3378, August 2004

The Policy Research Working Paper Series disseminates the findings of work in progress to encourage the exchange of ideas about development issues. An objective of the series is to get the findings out quickly, even if the presentations are less than fully polished. The papers carry the names of the authors and should be cited accordingly. The findings, interpretations, and conclusions expressed in this paper are entirely those of the authors. They do not necessarily represent the view of the World Bank, its Executive Directors, or the countries they represent. Policy Research Working Papers are available online at http:/lecon.worldbank.org.

\footnotetext{
* This paper has been prepared in the context of the "Pro-poor Growth" program sponsored by the World Bank's PREM Poverty Group. I would like to thank Oya Celasum, Aart Kraay, Ugo Paniza, Cico Ferreira, Tito Cordella, Ulrich Lachler and seminar participants at the World Bank, IMF, and IDB for comments received and to Peter Bocock for editorial assistance. Address for correspondence: MSN MC4-415, The World Bank, 1818 H Street, Washington, DC 20433. Email: Hlopez@worldbank.org. Tel: 1+202-4734909.
} 


\section{Introduction}

A large number of papers have recently explored the links between growth and inequality and the resulting impact on poverty reduction. Questions arising from this debate include whether the benefits of economic growth are broadly shared by all groups of society including the poor; whether a poverty reduction strategy should mainly have a growth bias; whether there are trade-offs between pro-growth and pro-poor growth strategies; and whether pro-growth policies are also the best poverty reduction policies. As a result of this debate, a few findings have emerged on which there seems to be a more or less broad consensus.

First, nobody seems to doubt the importance of growth for poverty reduction. Countries that have historically experienced the greatest reduction in poverty are those that have experienced prolonged periods of sustained economic growth. In fact, there is plenty of evidence suggesting that the poor typically do share from rising aggregate income and do suffer from economic contractions. This finding is robust to the use of a relative concept of poverty where the poor are a pre-specified proportion of the population - usually the lowest quintile of the population (Dollar and Kraay (2002), Foster and Szekely (2000)), or an absolute definition of poverty where the poor are those with income ${ }^{1}$ levels below a pre-specified threshold - for example PPP adjusted US\$1 per person per day, or a country-specific poverty line computed on the basis of the cost of a country-specific subsistence package (Ravallion and Chen (1997)).

Second, progressive distributional changes are good for poverty reduction. While on the one hand it is difficult to argue that poverty reduction can be achieved through redistributive policies in the absence of economic growth, growth associated with progressive distributional changes will have a greater impact in reducing poverty than growth that leaves the distribution unchanged. For example, Ravallion (1997), Bourguignon (2002), and Son and Kakwani (2003) review the poverty-growth-inequality relationship and note that the impact of growth on poverty is reduced when inequality is high. Poverty will therefore be more responsive to growth the more equal the income distribution. Intuitively, if the poor have a low share in existing income, they will likely have a low share in newly created income.

Third, there is no strong empirical evidence suggesting a general tendency for growth as such to make income distribution more or less equal. For example, Dollar and Kraay (2002) find that, on average, the income of the poorest fifth of society rises proportionately with average incomes. Other studies concluding that changes in income and changes in inequality are unrelated include Deninger and Squire (1996), Chen and Ravallion (1997) and Easterly (1999). Growth would thus be good for the poor, or at least as good as for everybody else in society.

From a policy perspective, however, there is another issue that is likely to be more interesting than the existence of empirical regularities between growth, inequality, and poverty, namely what kind of policies a country should pursue in a successful poverty reduction strategy. Since poverty outcomes will depend on how a given policy affects

\footnotetext{
${ }^{1}$ Strictly speaking many of the studies exploiting absolute definitions of poverty are based on per capita expenditure levels and use income levels only as a substitute on data availability grounds.
} 
growth and inequality, assessing how appropriate a particular policy is for a poverty reduction strategy will require knowledge about the links between policies and growth on the one hand and between those same policies and inequality on the other hand.

On the growth front, the literature is quite rich and there are several empirical models that offer guidance as to the expected impact that a particular policy may have on long-run growth. On the inequality front, one might take the result pointing to lack of causality from growth to inequality mentioned above at face value and select policies on the basis of their expected impact on growth. However, a number of recent papers have suggested that many pro-growth policies might be expected also to have an impact on inequality, and in some cases even conflict with the growth objective. For example, work by Barro (2000) and Lundberg and Squire (2003) suggests that greater openness to trade (something to be welcomed when one has a growth objective in mind) would go along with more inequality. Similarly, Li and Zou (2002) present empirical evidence suggesting that increases in government spending, while potentially leading to lower growth, would also reduce inequality. Thus advice based only on the expected growth impact of policies could lead to unpleasant poverty outcomes (as the anti-globalization movement has been pointing out repeatedly over the last few years). More generally, Easterly (2001) also finds that structural adjustment in the context of World Bank and International Monetary Fund programs tends to reduce the growth elasticity of poverty, a result that would be consistent with a positive relationship between increases in inequality and the implementation of adjustment programs. Easterly speculates that this may be due to the poor being ill placed to take advantage of the new opportunities created by structural adjustment reforms.

This paper enters this debate with the main purpose of providing an empirical evaluation of the impact of a number of pro-growth policies on inequality and headcount poverty. In doing so the paper contributes to the existing literature along several dimensions. First, following a similar framework to that in Lundberg and Squire (2003) and Li and Zou (2002), the paper takes into account the possibility that some policies may simultaneously influence both growth and inequality. However, contrary to other studies, we focus on the impact of policies on inequality changes (rather than on inequality levels). This seems the natural choice when interest centers on the impact of policies on poverty through growth and redistribution channels.

Second, unlike most of the empirical studies on inequality, we move beyond the assessment of the impact of policies on growth and the distribution of income, and combine these elements to infer, under plausible assumptions, potential changes in poverty. This issue is likely to be relevant and not only in the context of a strategy for poverty reduction or achieving the Millennium Development Goals. In fact, from a policy perspective, the weight given to the impact that a policy has on inequality is likely to be relative, and to depend on the contemporaneous impact of the policy on growth.

Third, our estimation results are based on dynamic panel models. In addition to taking into account the possibility of inequality convergence (Benabou (1996), Ravallion (2002)), this approach allows us to capture potential inter-temporal poverty dynamics. If after implementation of a pro-growth policy that has a negative impact on inequality there are important mismatches between when the growth and inequality effects become apparent, it would be plausible to find that a policy intervention increases poverty in the short run and decreases it in the long run. This would be the case if the inequality effect 
was felt immediately but there were important lags before the bulk of the growth effect became noticeable. The issue is of particular interest for policy analysis because of the potential political economy risks associated with reform programs that lead to temporary increases in poverty. Further, since growth models tend to adjust very slowly (empirical estimates of the half-life of convergence found in the literature range from 20 to 40 years), it would be possible that the increases in poverty would be temporary, but still long lasting.

Fourth, at a more technical level, we take into account the possibility of fixed effects in a dynamic panel framework. Fixed effects can appear if some countries have a tendency to be more equal owing to cultural or religious considerations; by controlling for them, it is possible to somewhat mitigate omitted-variable bias (at least with respect to timeinvariant unobservable country characteristics).

To anticipate some of the results below, we find that there is inequality convergence and that there is an apparent mismatch between the speeds of convergence of income and inequality, with inequality converging much faster than income. As indicated above, this could potentially lead to an increase in poverty when a policy presents a trade-off between its growth and inequality outcomes. On the growth-inequality links, we find a Kuznets type of relationship by which inequality rises with income levels up to about $\$ 3,000$ (1985 US dollars) and falls thereafter, and find no significant evidence of inequality per se affecting growth. Admittedly, the point estimate for inequality comes close to being significant at the 10 percent level, suggesting that higher inequality would lead to lower growth. However, even on the basis of the point estimate, our results suggest a small potential impact of inequality on growth: a 1 percent deterioration in the Gini coefficient would lead to an annual growth decline of .007 percent.

At the policy level, on the one hand, we find that improvements in education and infrastructure and lower inflation would reduce inequality. The estimates of the coefficients for these variables always have the expected sign and are highly significant from a statistical point of view. Thus policies in these areas support both higher growth and lower inequality, and hence have a positive effect on poverty reduction.

On the other hand, we find that financial development, trade openness, and decreases in the size of government would be associated with increases in inequality. Thus, policies in these areas present some conflict with respect to growth and inequality objectives. To the extent that their positive impact on growth offsets the negative impact on inequality, these pro-growth policies would also be pro-poor (in the sense that poverty falls as a result of the implementation of the policy). Under the assumption of a log normal income distribution, we illustrate the expected impact that progress on these areas may have on (headcount) poverty levels, and find that these policies are likely to be pro-poor in the long run (i.e. the growth effect offsets the increase in inequality), but might also lead to temporary short-run increases in poverty in the absence of compensatory measures.

We also find that financial crises would hit the better off harder than the poor and would therefore be associated with reduced inequality (but this is of little consolation when a crisis negatively affects growth and therefore the reduction in inequality occurs when poverty is increasing); that output volatility, in addition to slowing growth, would increase inequality (probably because the poor tend to be more vulnerable); that 
governance may be negatively related to inequality (in the sense that better governance would lead to more inequality); and that external imbalances, and terms of trade shocks have little impact on inequality (at least from a statistical point of view).

All in all, the findings of this paper suggest that pro-growth policies, regardless of their impact on inequality, are likely to be pro-poor in the long run. In other words, the positive impact that policies have on growth should be enough to eventually offset the potential negative effects they may have on inequality. However, there is also a need to face the possibility (and its associated implications) that some reform policies may lead to temporary increases in poverty. This is especially the case given that in this framework "temporary" may span several years.

The rest of the paper is structured as follows. In section II we review some basic growthinequality-poverty relationships that stress the important inter-relations between growth and inequality for poverty reduction. Sections III to V provide an empirical evaluation of the impact of a number of pro-growth policies on inequality. In Section III we discuss the econometric models and how they can be used to infer the impact that different policies have on poverty. Section IV addresses econometric issues, paying particular attention to the challenges involved in the estimation of a dynamic panel with country-specific effects, and reviews the data used in the empirical section. In section $\mathrm{V}$ we present the results for the empirical inequality model, and in section VI we link the growth and inequality results to draw inferences about the likely impact that changes in the policy determinants under consideration may have on poverty. Section VII closes the paper with some conclusions.

\section{Growth, inequality and poverty}

The degree of poverty in any given country depends upon two factors: the average income level of the country and the extent of income inequality. Formally,

$P=P(Y, L(p))$,

where $P$ is a poverty measure (which for simplicity will be assumed to belong to the Foster-Greer-Thorbecke (FGT) (1984) class $^{2}$ ), $Y$ is per capita income and $L(p)$ is the Lorenz curve measuring the relative income distribution. $L(p)$ is the percentage of income enjoyed by the bottom $100 \times p$ percent of the population.

Changes in poverty can be decomposed into a growth component that relates changes in $Y$ to $P$, and an inequality component that relates poverty to changes in inequality. In general, increases in average income (growth) will reduce poverty. Thus, denoting the growth elasticity of poverty by $\gamma$ one could write:

2 The FGT class of poverty measures is given by $P_{\alpha}=\int_{o}^{z}\left[\frac{z-x}{z}\right]^{\alpha} f(x) d x$ where $\alpha$ is the parameter of inequality aversion, $z$ is the poverty line, and $x$ is income. For $\alpha=0$, the previous expression reduces to the familiar headcount ratio. When $\alpha=1$ it weights each poor person by his/her distance form the poverty line (the poverty gap), and when $\alpha=2$ the weight given to each poor person is proportional to the square of the income shortfall (squared poverty gap). Put in other words, higher values of $\alpha$ would give more weight to the extreme poor than to those groups closer to the poverty line $z$. 
$\gamma=\frac{\partial P}{\partial Y} \frac{Y}{P}<0$

Measuring the effect of inequality on poverty is slightly more complex because inequality can change in infinite ways. Although intuitively progressive distributional change is likely to reduce poverty ${ }^{3}$, this result cannot be generalized without additional assumptions. For example, consider the (possibly unlikely) case of a transfer from the extremely rich to the very (but not extremely) rich. This would improve inequality levels but would not affect poverty. To make the problem of the impact of inequality changes on poverty tractable, one possibility is to assume that income follows a log-normal distribution. ${ }^{4}$ Lopez and Serven (2004) compare the theoretical quintile shares according to a log-normal distribution with their empirical counterparts using data from 794 household surveys and conclude that the log normal approximation fits the empirical data extremely well. In turn, under this assumption it is possible to express the inequality elasticity of poverty $\phi$ as the elasticity of poverty with respect to the Gini index $G$ :

$\phi=\frac{\partial P}{\partial G} \frac{G}{P}>0$

With these elements in mind, a change in poverty due to a change in policy $\mathrm{X}$ can be expressed as:

$\frac{\partial P}{\partial X} \frac{X}{P}=\frac{\partial Y}{\partial X} \frac{X}{Y} \frac{\partial P}{\partial Y} \frac{Y}{P}+\frac{\partial G}{\partial X} \frac{X}{G} \frac{\partial P}{\partial G} \frac{G}{P}$,

or using (2) and (3) above

$\frac{\partial P}{\partial X} \frac{X}{P}=\frac{\partial Y}{\partial X} \frac{X}{Y} \times \gamma+\frac{\partial G}{\partial X} \frac{X}{G} \times \phi$

Equation (5) indicates that the impact that a change in policy $\mathrm{X}$ will have on poverty will depend on: (i) the impact that the policy has on growth; (ii) how growth is translated into poverty reduction; (iii) the simultaneous impact that the policy has on inequality (as measured by the Gini coefficient), and finally (iv) how inequality changes are translated into poverty reduction.

In principle, $\gamma$ and $\phi$ could be considered to be independent of the policy in question and depend on the particular income distribution, the initial level of per capita income $Y$, the poverty line, and the initial level of inequality $G .^{5}$ Table 1 presents the theoretical elasticities of headcount poverty to growth and headcount poverty to inequality computed under the assumption that income follows a log normal distribution. These elasticities are

\footnotetext{
${ }^{3}$ Strictly speaking, for the inequality elasticity of headcount poverty to be positive it is also required that the level of average per capita income is above the poverty line. Otherwise, there is the risk that progressive distributional changes increase poverty.

${ }^{4}$ If the distribution of income $y$ is $\log$-normal, then $\log (y) \sim N(\mu, \sigma)$, with $G=2 \Phi(\sigma / \sqrt{ } 2)$-1 where $\Phi($.) denotes the cumulative normal distribution (Aitchinson and Brown (1966)), and $\mathrm{G}$ is the Gini index.

${ }^{5}$ See Son and Kakwany (2003) for an excellent review of the relationship between inequality, average income and the elasticities of poverty.
} 
computed for different Gini coefficients (running from .3 to .6) and different levels of development (expressed in terms of the share of the poverty line to per capita GDP) ${ }^{6}$ (see Lopez and Serven (2004)).

For example, for a country where the poverty line is 33 percent of per capita income and the Gini coefficient is .3, the growth elasticity of poverty would be -4 (i.e. growth of 1 percent of GDP would reduce poverty by 4 percent) whereas the inequality elasticity would be 5.2 (a 1 percent increase in the Gini coefficient would increase poverty by 5.2 percent). By contrast, in a country with the same income level but higher inequality, say a Gini of .6, the growth elasticity of poverty would be -.9 , and the inequality elasticity would be 2 . Thus high initial inequality levels are likely to represent a barrier to poverty reduction, since both the impact of growth on poverty ${ }^{7}$ and the impact of progressive distributional change on poverty will be much smaller than in countries with a more equal income distribution.

On the other hand, it is also the case that high initial poverty is also a barrier for poverty reduction. For example, consider the case of a country with a Gini of .4. If the country had per capita income levels that are six times the poverty line (row with the heading .16 in table 1) the growth elasticity of poverty would be -3.3 , whereas if the country had income levels that are only one and half times the poverty line (row with the .66 heading in table 1), this same elasticity would only be -1.2 . Thus this second (and poorer) country would have to achieve a growth rate that is more than twice that of the first (and richer) country to obtain the same rate of poverty reduction. Similarly, a 1 percent decline in the Gini coefficient would lower poverty by .9 percent when a country has a Gini coefficient of .4 and the poverty line is 66 percent of per capita income levels, but would have a much higher impact ( 7.7 percent) when the poverty line is 16 percent of per capita income.

\section{The impact of policies on growth and inequality}

The previous section has reviewed the role that growth and inequality levels play for poverty reduction. It has also highlighted the fact that inferences about how a particular policy will affect poverty require knowledge about the impact of the policy on both growth and inequality. On the growth front, the literature is quite rich and there are several empirical models that offer guidance as to the expected impact that a particular policy may have on long-run growth. On the inequality front, however, not only is the literature less rich but also in most cases it is based on empirical models that relate the level (rather than the change in the level) of inequality to policies and therefore complicate the analysis of poverty.

The empirical models in this paper are based on the following dynamic structure:

$$
\begin{aligned}
& y_{i t}-y_{i t-1}=\delta y_{i t-1}+\omega^{\prime} x_{i t}+v_{i}+\tau_{t}+v_{i t}, \\
& g_{i t}-g_{i t-1}=\alpha g_{i t-1}+\beta^{\prime} x_{i t}+\mu_{i}+\eta_{t}+\varepsilon_{i t},
\end{aligned}
$$

\footnotetext{
${ }^{6}$ If one considers a typical poverty line, say US\$1 per person per day, the reported elasticities would correspond to the following per capita income levels: US\$2190 (.16), US\$1095 (.33), US\$730 (.5), US\$547 (.66), US\$405 (.90) and US\$331 (1.1).

${ }^{7}$ This point was first made by Ravallion (1997).
} 
where $y$ is the log of per capita income, $g$ is the log of the Gini coefficient, $x$ represents the set of explanatory variables other than the lagged measure of income, $v$ and $\mu$ are unobserved country-specific effects, $\tau$ and $\eta$ are time-specific effects and $v$ and $\varepsilon$ are the error terms. The subscripts $i$ and $t$ represent country and time period.

Beyond expressing the impact that the coefficients of the different policies may have on growth and inequality, (6) and (7) can be employed to obtain estimates of how poverty changes would be associated to a change in policy $j$ of $x$. It must be noted, however, that the presence of dynamics allows us to differentiate between the immediate impact that a change in a given policy has on both income and inequality and the long-run impact that results from the dynamic feedback. For example, changes to policy $j$ will lead in the short run to: ${ }^{8}$

$$
\frac{d p}{d x_{j}}=\omega_{j} \times \gamma+\beta_{j} \times \phi
$$

where $p$ is the $\log$ of the poverty measure, whereas in the long run they will lead to: ${ }^{9}$

$$
\frac{d p_{L R}}{d x_{j}}=-\frac{\omega_{j}}{\delta} \times \gamma-\frac{\beta_{j}}{\alpha} \times \phi .
$$

Clearly, if the dynamics in equations (6) and (7) are similar (i.e. if $\delta$ is similar to $\alpha$ ) then (9) reduces to (8) scaled up to $\delta=\alpha$. But if one of the variables adjusts much faster than the other then one should also expect to find dynamics in poverty. Figure 1 illustrates this point with a very simple example that assumes $\gamma=-\phi=1, \delta=-.1, \alpha=-.3, \beta=.6$ and $\omega=.3$. This parametrization would be consistent with a policy that has a positive impact on growth and a negative impact on income distribution; in addition the full impact on distribution is felt much faster than on growth. Inspection of figure 1 would suggest an initial net adverse impact on poverty (due to the increase in inequality) that later is reversed and, as the impact of the policy on income kicks in, poverty is reduced.

The models in (6) and (7) are based on the implicit assumption that simultaneous changes in income and in inequality are motivated by the implementation of a given policy, and ignore the potential impact that growth "as such" may have on inequality and that inequality "as such" may have on growth. While in principle the existing empirical evidence seems to suggest that the growth process is not accompanied by changes in inequality, some authors have also found a Kuznets type of relationship between inequality and income levels. For example, Barro (2000) finds that the Gini index would rise with GDP for values of GDP of less than \$1636 (in 1985 US dollars) and fall thereafter. Also, assuming that inequality has no impact on growth seems a bit more controversial. Benabou (1996), Perotti (1996), and Alesina and Rodrik (1994) find that inequality negatively affects growth, whereas Forbes (2000) and Li and Zou (1998) find

\footnotetext{
${ }^{8}$ Strictly speaking one should also consider an error term emerging from using a discrete approximation to an infinitesimal interval.

${ }^{9}$ This assumes that $\delta \neq 0$ and $\alpha \neq 0$. If the parameter controlling the dynamics is zero, all the adjustment would take place immediately.
} 
the opposite result. To take into account potential interactions we also consider the following models: ${ }^{10}$

$$
\begin{aligned}
& y_{i t}-y_{i t-1}=\delta y_{i t-1}+\omega^{\prime} x_{i t}+\xi g_{i t}+v_{i}+\tau_{t}+v_{i t}, \\
& g_{i t}-g_{i t-1}=\alpha g_{i t-1}+\beta^{\prime} x_{i t}+\chi y_{i t-1}+\mu_{i}+\eta_{t}+\varepsilon_{i t} .
\end{aligned}
$$

Equations (10) and (11) would now result in different expressions for the changes in poverty levels which in this case would be given by:

$$
\begin{aligned}
& \frac{d p}{d x_{j}}=\left(\omega_{j}+\xi \beta_{j}\right) \times \gamma+\beta_{j} \times \phi \\
& \frac{d p_{L R}}{d x_{j}}=-\frac{1}{(\delta \alpha-\chi \xi)}\left(\alpha \omega_{j}-\xi \beta_{j}\right) \times \gamma-\frac{1}{(\delta \alpha-\chi \xi)}\left(\delta \beta_{j}-\chi \omega_{j}\right) \times \phi .
\end{aligned}
$$

It is evident that for $\xi=\chi=0,(12)$ and (13) reduce to (8) and (9).

With respect to policies, we follow recent work by Loayza and Soto (2002) and Loayza, Fajnzylber and Calderon (2002) who propose an empirical growth model that focuses on policies that have received the most attention in academic and policy circles, and especially at the World Bank, in the context of structural adjustment operations. In addition to the lagged dependent variable, the following regressors are considered: cyclical reversion (captured by the output gap); human capital (logged rate of gross secondary enrollment); financial development (logged ratio of private domestic credit supplied by private financial institutions to GDP); government burden (logged ratio of government consumption to GDP), infrastructure (telecommunications capacity), governance/institutions (first principal component of the four indicators reported by the International Country Risk Guide - prevalence of law and order, quality of bureaucracy, absence of corruption, and accountability of public officials), trade openness (volume of trade adjusted by country size - area and population - whether the country is landlocked, and whether it is an oil exporter), inflation rate, cyclical volatility (standard deviation of the output gap), real exchange rate misalignment, banking crisis (number of years that a country undergoes a banking crisis in the period under analysis), and terms of trade changes.

\section{Estimation and data issues}

Estimation of equations (6) and (7) (or equivalently (10) and (11)) above poses several challenges including the presence of country-specific effects and the possible endogeneity of some of the explanatory variables with inequality. Arellano and Bond (1991) propose differencing the equations to eliminate country-specific effects. After

${ }^{10}$ Observe that the implicit restrictions in the system given by (10) and (11) are enough to have an identified system. 
accounting for time-specific effects (with the inclusion of period-specific dummies), equation (7) could be rewritten as ${ }^{11}$ :

$$
\left(g_{i t}-g_{i t-1}\right)-\left(g_{i t-1}-g_{i t-2}\right)=\alpha\left(g_{i t-1}-g_{i t-2}\right)+\beta^{\prime}\left(x_{i t}-x_{i t-1}\right)+\left(\varepsilon_{i t}-\varepsilon_{i t-1}\right),
$$

or

$$
\left(g_{i t}-g_{i t-1}\right)=(1+\alpha)\left(g_{i t-1}-g_{i t-2}\right)+\beta^{\prime}\left(x_{i t}-x_{i t-1}\right)+\left(\varepsilon_{i t}-\varepsilon_{i t-1}\right) .
$$

This differencing, however, introduces a new bias since the error term $\left(\varepsilon_{i t}-\varepsilon_{i t-1}\right)$ is correlated with the lagged dependent variable $\left(g_{i t-1}-g_{i t-2}\right)$. Under the assumptions that the error term $\varepsilon$ is not serially correlated, Arellano and Bond (1991) propose a two-step generalized methods of moments (GMM) estimator using as moment conditions:

$$
E\left[g_{i t-s}\left(\varepsilon_{i t}-\varepsilon_{i t-1}\right)\right]=0 \text { for } \mathrm{s} \geq 2
$$

and if the explanatory variables $x$ are predetermined but not strictly exogenous:

$$
E\left[x_{i t-s}\left(\varepsilon_{i t}-\varepsilon_{i t-1}\right)\right]=0 \text { for } \mathrm{s} \geq 2 \text {. }
$$

In the first step, the error terms are assumed to be independent and homoskedastic across countries and time. In the second step, the residuals obtained in the first step are used to construct a consistent estimate of the covariance matrix, and thus relax the assumptions of independence and homoskedasticity. Using the moment conditions in (16) and (17) and denoting $\theta=[\alpha \beta]$ ', the GMM estimator of $\theta$ and corresponding covariance matrix $\Sigma_{\theta}$ are given by:

$$
\begin{aligned}
& \hat{\theta}=\left(\bar{x}^{\prime} Z \hat{\Omega}^{-1} Z^{\prime} \bar{x}\right)^{-1} \bar{x}^{\prime} Z \hat{\Omega}^{-1} Z^{\prime} g \\
& \hat{\Sigma}_{\theta}=\left(\bar{x}^{\prime} Z \hat{\Omega}^{-1} Z^{\prime} \bar{x}\right)^{-1}
\end{aligned}
$$

where $\bar{x}=\left[g_{i t-1} x\right], Z$ is the matrix of instruments, and $\hat{\Omega}$ is a consistent estimate of the covariance matrix of the moment conditions constructed with the residuals of the first step regression.

The consistency of the GMM estimator above depends on the validity of the assumption that the error terms do not exhibit serial correlation as well as on the validity of the instruments. We present two specification tests to address these issues. The first is the Sargan test of overidentifying restrictions. The second test examines whether the error term $\varepsilon$ is not serially correlated, which in turn would imply that the difference error in (14) does not present second-order serial correlation.

We rely on two main sources of data. Inequality data come from Dollar and Kraay's database on inequality. This database expands the inequality data used in their 2002 paper and contains 953 observations of the Gini coefficient for 137 countries. We acknowledge that the Gini coefficient is less than perfect and that other measures, such as the income

${ }^{11}$ Clearly, equation (6) would also be subject to a similar transformation. 
share of the lowest quintile, may be more appropriate. Data availability, however, dictates the choice. ${ }^{12}$ The growth determinants come from Loayza, Fajnzylber, and Calderon (2002).

Our regressions are conducted using non-overlapping five-year periods spanning the years 1960-2000. Income and inequality data are taken from the latest available date within the given period. Growth and inequality determinants are averages for the fiveyear period in question. These transformations would reduce the sample to 291 observations for 87 countries for which we have at least 2 consecutive Gini coefficients. If we also eliminate countries with less than 3 observations (note that as implied by (16) and (17) we need a minimum of three observations per cross-section unit to run the GMM estimator outlined above), the sample is further reduced to 194 inequality observations for 61 countries.

The original sample of growth determinants is higher and includes data for 78 countries and the total number of observations is 350 . When both databases are merged, however, the number of observations available for estimation purposes is reduced to 134 cases and 41 countries. Working with five-year averages reduces the problems associated with the original panel where 24 countries would account for more than half of the 953 observations. Further, the use of at least three observations for each country (i.e. 15 years) gives a long-run perspective to the problem that is lost with the original panel, where more than 30 countries have only one observation.

Admittedly, using five-year periods also brings some complications. For example, the sample size is notoriously reduced from the original inequality database. The reduction in the number of observations is particularly important when one considers the estimator proposed above, since we are working with a large number of variables and a small crosssection dimension (41 countries in some cases). For example, if we were to consider the explanatory variables as predetermined, even limiting the maximum number of lagged levels to be used as instruments to two, we would still end up with 170 instruments in some of our specifications. Not only does the problem then become too large to estimate, but also the excessive number of overidentifying restrictions relative to the sample would dramatically affect the performance of the GMM estimator. Against this background, the results presented below for the models including all the policies treat as a predetermined variable only the lagged dependent variable. Since the model is still overidentified, we can test the validity of the hypothesis that the proposed instrument set is uncorrelated with the error term, using the Sargan test for overidentifying restrictions. It must be noted in this regard that the employed specification tests generally support the econometric models. That is, Sargan and second-order correlation tests cannot reject the hypothesis that the models are well specified and that our instrument set is valid. ${ }^{13}$

Table 2 presents some descriptive statistics for the data. The logged Gini coefficient, would have a mean value of -.977 (equivalent to a Gini of about .37) and show considerable dispersion (the 2 standard deviation confidence interval would range from about -.43 to -1.51 ). The maximum logged Gini in the sample is -.296 and the minimum is -1.79 . There is also some evidence of a skewed distribution with a long and thin upper

\footnotetext{
${ }^{12}$ For example, using the growth rate in the income of the lowest quintile of the population would leave us with only one third of the observations we manage to use for the Gini regressions.

${ }^{13}$ The only exception to this rule is the regression of growth on the initial value of income.
} 
tail (revealing the presence of few very unequal countries in the sample). Regarding changes in the (log) Gini, the average annual change between two five-year periods would be .1 percent, indicating that on average inequality changes little over time. However, there is considerable dispersion: the 2 standard deviation interval would range from about -6.8 percent to 6.8 percent. The changes in the Gini coefficient also present a skewed distribution but in this case it is toward the lower tail. As for the income data, average annual growth rates between two five-year periods would be about 2 percent, but dispersion is also high (very similar to that found in the changes in the Gini coefficient). The variables that aim to represent the various aspects of economic development tend to be skewed toward the lower tail, something that would reveal the presence of a few very underdeveloped countries in the sample. The inflation rate also presents a skewed distribution but in this case is likely to reflect a few instances of extreme macroeconomic mismanagement.

\section{Empirical results}

We start this section by presenting results for equations (10) and (11) under the restriction that $\beta=\omega=0$. Thus equation (11) is basically reduced to a test of convergence for inequality considering the potential impact of income levels, whereas in equation (10) we explore, in addition to the speed of convergence for per capita income levels, the potential impact of inequality on growth. We estimate the equations with four different methods: OLS, fixed effects, 2SLS ${ }^{14}$, and the Arellano and Bond (1991) GMM estimator. In turn, we present the results of the Arellano and Bond estimator treating the nonlagged-dependent-variable regressor both as an exogenous variable and as a predetermined variable.

Inspection of table 3 suggests convergence in inequality levels, with the estimators that take into account the possibility of fixed effects resulting in a faster speed of convergence. For example, while the pooled estimator suggests a half-life of about 20 years, the other estimators suggest a half-life of between 1 and 5 years. These results are consistent with the findings of Benabou (1996) and Ravallion (2002) ${ }^{15}$ who also find inequality convergence. Further, their estimated coefficients for the speed of convergence are of a similar order of magnitude to our pooled estimator. Two possible interpretations behind the inequality convergence given by Ravallion are related to (i) the implications of the neoclassical growth model (which in addition to predicting income convergence across countries would also predict inequality convergence), or more pragmatically to (ii) the widespread convergence of economic policy during the 1990s. This second argument is likely to weigh less, however, when we take into account the fact that we also find inequality convergence when we control for policy changes, and therefore for policy convergence. As for the impact of initial income on the changes in inequality, table 3 does not find any significant effect, although admittedly, given how parsimonious the models are, this could be due to omitted variables bias.

\footnotetext{
${ }^{14}$ In equation 10 the instruments are 3 lagged growth observations and inequality with 3 lagged values of inequality. In equation (11) lagged inequality is instrumented with lagged changes in inequality and initial per capita income in equation (10) is instrumented with 3 lagged growth observations. These instruments would be valid even in the presence of fixed effects.

${ }^{15}$ Ravallion uses a different estimation technique. Rather than relying on the relation between initial Gini and the subsequent change in the index, Ravallion (2002) measures the speed of convergence by comparing estimated trends in inequality with predicted initial levels of inequality.
} 
Next we explore in table 4 the results obtained when one regresses per capita growth on initial income and inequality. Two main messages emerge from this table. First, the speed of convergence in per capita income levels seems to be much lower than the speed of convergence for inequality, with an estimated half-life of between 8 years (A\&B estimators) and 40 years (2SLS estimator). The fixed-effects estimator would suggest a half-life of 18 years, and the pooled estimator cannot reject a null hypothesis of no convergence. These results would suggest that in principle, following a shock of a similar magnitude to both inequality and growth, ${ }^{16}$ the adjustment process in inequality would be much shorter than the adjustment in per capita income levels. In turn, as noted above this could produce poverty dynamics where poverty increases initially but then subsequently decreases. The second message emerging from the table is that inequality as such does not seem to affect growth. This finding would be half way between those of Alesina and Rodrik (1994) and Perotti (1996), who find evidence that inequality negatively affects growth, and those of Li and Zhou (1998) and Forbes (2000), who find a positive relationship between inequality and growth. It could be argued that this result is somewhat driven by the combination of countries at different levels of development. As noted by Galor (2000) it is possible to construct models where in the early stages of development inequality positively affects growth prospects, but in later stages negatively affects growth. To further explore this issue, table 5 presents the results obtained when the previous growth regression is run for three different samples: low, middle and highincome countries. The results, however, remain virtually unchanged.

Moving now to address the impact of different policies on growth and inequality, table 6 reports in its first and second columns the results of two empirical growth models. The first column reports the results obtained by Loayza and Soto (2002). The second column augments that model with inequality. Two basic messages emerge from these models. First, inequality carries a negative sign (more inequality would be bad for growth) and even if it is not statistically significant at the 10 percent level, it comes quite close. However, even if one were to judge from the point estimate, our results suggest a small potential impact from inequality to growth: a 1 percent deterioration in the Gini coefficient would lead to an annual growth decline of .007 percent. Second, not surprisingly given the lack of an apparent role for inequality in the growth specification, the point estimates of the coefficients of the different policies are very similar to those obtained by Loayza and Soto. There is, however, one improvement when one includes inequality: governance now appears to positively affect growth whereas in the Loayza and Soto specification it carried a negative sign (better governance would be associated with slower growth). ${ }^{17}$

As for the models for inequality, table 6 presents estimates for three models. Two of them correspond to equations (7) and (11), whereas the third one is an augmented version of the model in (11) that takes into account possible non-linearities in the level of income (and thus tries to capture a potential Kuznets curve relationship between inequality and income levels). Overall we now find evidence suggesting that income levels may have an impact on changes in inequality. When the basic model is augmented with the initial level of GDP per capita we obtain a negative (and significant) relationship between income levels and changes in inequality (higher income levels would be associated with

\footnotetext{
${ }^{16}$ This would be consistent with growth and the changes in the log Gini having a similar standard deviation.

${ }^{17}$ Loayza and Soto (2002) results, however, are more efficient in general.
} 
lower inequality levels). When we consider initial income and its square among the explanatory variables, the last column in table 6 would indicate that there appears to be an inverted-U relationship between the Gini value and income. In fact, this relationship would indicate that the Gini coefficient rises with GDP per capita values of less than US\$2940 (1985 dollars) and declines thereafter. We also find that including the initial level of GDP among the regressors does not significantly affect the estimates of the coefficients of the policy variables under consideration. We next consider these.

The results for education would indicate that countries with better education (as measured by secondary enrollment rates) would be less unequal. The estimated coefficients are very similar in the three empirical models for inequality and of a similar order of magnitude to those in the growth model. These results are in line with those of Datt and Ravallion (2002) and Lundberg and Squire (2003). Using 20 household surveys for India's 15 major states, Datt and Ravallion (2002) also conclude that poor basic education is an impediment to the ability of the poor to participate in opportunities for economic growth. Lundberg and Squire (2003) also find that education is likely to be correlated with both faster growth and lower income inequality.

The estimated coefficient for financial development is always significant and suggests that progress on this front would be associated with increases in inequality. Possible explanations for this finding are: (i) the more educated (and likely richer) are able to exploit the new opportunities better; (ii) adoption of capital intensive technologies is likely to substitute for unskilled labor. Thus to some extent, our results would support the findings of Behrman, Birdsall and Szekely (2001) who used household data over more than two decades for 17 Latin American countries to estimate that the financial sector liberalization reforms that took place during the 1990s negatively affected income distribution. Within a cross-country framework, Dollar and Kraay (2002) also find that financial development negatively affects inequality.

Contrary to financial development, where most of the available empirical results already suggest that more financial development implies more inequality, the available results for trade openness point toward less than unanimous conclusions. Dollar and Kraay (2002) find that trade openness positively affects income distribution. A similar result is obtained by Behrman, Birdsall and Szekely (2001) for a set of Latin American countries. However, Sanchez and Schady (2003) find the opposite result in six Latin American countries, where trade volumes would negatively affect inequality. Spillimbergo et al (1999) and Barro (2000) also find that trade openness would be associated with higher inequality, whereas Lundberg and Squire (2003) conclude that there seems to be a positive correlation between the Sachs-Warner index of trade liberalization and the Gini coefficient. Our results give some support to the view that trade may lead to higher inequality. The estimate of the trade coefficient is always positive and significant. Moreover, its magnitude is sizeable in the sense that it is larger than the coefficient found in the growth regressions.

As with trade openness and financial development, our results suggest that cutting the size of the government is likely to lead to faster growth, but also to increases in inequality. The estimated coefficient for this variable is always statistically significant even at the 1 percent level. Thus, there is at least some evidence that governments may be inefficient (i.e. more government means less growth) but maybe with a benevolent face (i.e. more government increases equality). This result is consistent with the findings of $\mathrm{Li}$ 
and Zou (2002), who also find that higher spending, while having a negative impact on growth, may positively affect inequality levels.

Public infrastructure, on the other hand, is an area that belongs to the win-win category of policies (i.e. policies that both increase growth and reduce inequality). That is, not only would society as a whole be better off but also the poor would benefit more than proportionately. As noted by Ferreira (1995), productive public investment can potentially alleviate inequality even if expenditures are uniformly distributed. This would be the case if the poorest groups of society face a credit constraint that prevents them from acquiring private substitutes for infrastructure, whereas the richest class is able to complement the free public provision of these services.

The result for the governance variable may be somewhat controversial. Here we find that better governance would lead to more unequal societies. One possible reason for this finding is that once we control for policies, a country's preferred level of inequality is not related to the level of governance. However, and given the result obtained in the basic growth regression (governance would negatively affect growth), this outcome could also be due to problems with the variable we use to capture the level of governance in the different countries.

As for macroeconomic stability, the estimated coefficient of inflation indicates that inflation penalizes the poor and that countries with lower inflation would have a tendency to be more equal. Given that low inflation is also positively associated with faster growth, polices aimed at reducing inflation would also belong to the win-win category. This result would, therefore, be in line with the findings of Easterly and Fisher (2001), Romer and Romer (1998), Beherman, Birdsall and Szekely (2001), and Lundberg and Squire (2003) who also find that high inflation and macroeconomic instability are negatively associated with the incomes of the poor.

Regarding financial crises, our results suggest that in turbulent times (at least in those countries where the turbulence is created by a financial crisis) inequality would fall. Sanchez and Schady (2003) find a similar result for a sample of six Latin American countries and explain it by noting that important downturns in the demand for tertiary educated workers are highly correlated with economic downturns. Similarly, the Asian financial crisis that started in 1997 seems to have affected more young adult urban workers working in relatively well paid construction and financial sectors than the allegedly most vulnerable groups (Behrman, Deolalikar and Tinakron, 2000 and 2001) and therefore contributed to a reduction in inequality. Clearly, one has to also note that since overall per capita income is also falling this is likely to be of little consolation for the poor who in effect will be worse off regardless of the changes in inequality.

The volatility of the business cycle is also positively related to the Gini coefficient (sharper economic fluctuations would be associated with higher inequality), although admittedly in the basic inequality specification the standard deviation of the output gap is not significant. A possible explanation behind the finding suggesting that the amplitude of the business cycle is associated with higher inequality levels is that poorer groups in society would likely find it more difficult to insure themselves against sharp fluctuations in output growth. 
As for exchange rate management policies (i.e. the degree of overvaluation), the coefficient is insignificant. This is another case where the findings of the empirical model seem to be counterintuitive: given that real exchange overvaluation would capture distortions in the allocation of resources between the tradable and the non tradable sectors, one could a priori expect this variable to play an important role in explaining the evolution of income distribution. Finally, regarding the evolution of the terms of trade, we find this variable also to negatively affect inequality (an improvement in the terms of trade would lead to a deterioration in income inequality), a finding that would be in line with the impact of trade on inequality.

\section{Poverty impact of policies.}

The previous section has reviewed the main results obtained when one relates inequality to a broad set of policy variables. Overall the inequality model would suggest that there are some win-win policies (education, infrastructure, and macroeconomic stability) that could be associated with growth and progressive distributional change. That is, the poor would benefit from growth more than proportionately. However, we have also found policies that present trade-offs in the sense that they push inequality and growth in different directions. Among these policies, one could mention cuts in the size of government, financial development, and trade openness.

From a policy perspective, however, the weight given to the impact that a policy has on inequality is likely to be relative and to depend on the relative importance of inequality with respect to growth. The metric we use here is given by the overall impact of the policy on poverty as discussed in section II above ${ }^{18}$. Furthermore, the framework reviewed allows us to discriminate between the short and long-run poverty impact of policies, something that is particularly appropriate in this context given that the estimated parameter of the lagged dependent variable in the inequality regressions is about 10 times the corresponding estimate for the income regression model (that is, given the different speeds of convergence). The presence of dynamics may eventually imply that policies that are pro-poor in the long run (in the sense that poverty falls as a result of their implementation) are not so pro-poor in the short run.

Tables 7 to 10 present the net growth elasticities associated with those policies that present growth-inequality conflicts (government size, financial development, and trade openness) and also for three policies that do not present any such conflict (education, infrastructure and inflation). In tables 7 and 8 we do not allow for any feedback effect from inequality to growth or from income levels to changes in inequality. That is, tables 7 and 8 are based on expressions (8) and (9). In tables 9 and 10 we allow for feedback from income levels to inequality. Thus these tables are based on expressions (12) and (13) with $\xi=0$. Tables 7 and 9 focus on short-run impacts and tables 8 and 10 on the long run. In order to deal with the country specificity of the gross elasticity of poverty to growth and the elasticity of inequality to growth, we assume that income follows a log-normal distribution and present results based on the elasticities reported in table 1 .

\footnotetext{
18 Admittedly, it is possible to find examples where expression (5) proves too general. For example, Ferreira and Leite (2003) present evidence for Brazil suggesting that the observed reductions in inequality during the 1990 s were not beneficial to the bottom of the distribution.
} 
Inspection of tables 7 and 9 suggests that in the short run, the net elasticity of poverty of the three policies that have growth and distributional change pushing in the same direction (i.e. education, infrastructure and lower inflation) is always negative. In other words, progress on those fronts would lead to lower poverty. It is worth noting that the different elasticities vary significantly depending on initial conditions as given by levels of development and inequality, something that would suggest that initial conditions matter when choosing policies designed to support a poverty reduction strategy. In the cases where growth and progressive distributional change tend to move in different directions, the sign of the elasticity would be negative in most cases. The exception is government size, where the sign depends on initial country conditions, with the growth effect dominating in poorer and more equal countries, and the inequality effect dominating in richer and more unequal countries. Thus, depending on the country's income level, fiscal adjustment is likely to have a different impact on poverty.

When we focus on long-run elasticities (tables 8 and 10) the first conclusion we reach is that allowing for feedback effects from income levels to inequality does not alter the main result significantly: all the pro-growth policies would lead to reductions in poverty. This is regardless of the impact that these policies may have on inequality. In other words, in the long run, a pro-growth strategy will benefit the poor. Admittedly, it could be argued that, regardless of their long-run effect, the fact that some policies may temporarily increase poverty would be enough to exclude them from a poverty reduction strategy. In this regard, there is a need for a couple of clarifications. First, there is some evidence (Gallego and Loayza (2002)) that economic development is likely to follow a multiplicative model where what matters is not only the "quantity" of an implemented policy but also the overall policy mix. Thus it seems difficult to assume that a poverty reduction strategy can be uniquely based on policies such as education or infrastructure without addressing bottlenecks in other areas such as the financial sector, or external trade distortions. This would suggest that focusing on a few areas is likely to lead to disappointing results. Second, the equations above allow us to measure the impact of a policy change on poverty, other things being equal. However, assuming that other things are equal when there is growth seems unrealistic. Faster growth and therefore, higher per capita income levels, will in turn allow the implementation of education or infrastructure policies that would feed back into the growth process and also reduce inequality. Further, it is unlikely that investments in priority sectors could be significantly stepped up in the absence of additional growth that generates the required resources.

That said, however, we do not want either to minimize the potential negative impact that some policies, even if temporarily, can have on poverty, especially when "temporary" in this context may refer to several years. In fact, we take the results of this paper as an indication of the need to support pro-growth policies but (i) taking into account the risks (in terms of short-run increases in poverty) that might be associated with reform

programs and (ii) in parallel to pro-poor interventions that minimize the damage caused by the potential deterioration in income distribution.

\section{Conclusions}

This paper has reviewed, from a cross-country perspective, the impact of a series of progrowth policies on inequality and headcount poverty. The main contributions of the paper to the literature are that it: (i) explores the poverty impact of a number of policies usually considered in the growth literature through the projected interaction of growth and 
inequality; (ii) allows for the possibility of income and inequality dynamics which in turn allows for poverty dynamics; (iii) relies on a large database of non-overlapping five-year averages that mitigates to some extent the problems encountered when the distribution of surveys across countries is very unequal (countries with 40 surveys against others with just 1 or 2); and (iv) allows for fixed effects in a dynamic panel framework.

The findings of the paper suggest the likelihood of inequality convergence, and that the speed of convergence for inequality is faster than the speed of convergence for per capita income levels. On the growth-inequality links, we find a Kuznets type of relationship by which inequality would increase with income levels up to about $\$ 3,000$ (1985 US dollars) and decrease thereafter, and find no significant evidence of inequality affecting growth. Admittedly, the point estimate for inequality comes close to being significant at the 10 percent level, suggesting that higher inequality would lead to lower growth.

On the policy front, we find that improvements in education and infrastructure and lower inflation levels would lead to both growth and progressive distributional change. Financial development, trade openness, and cuts in the size of the government, all policies that would lead to faster growth, would be associated with increases in inequality. We also find that financial crises would be associated with reductions in inequality.

On the interaction between growth and inequality, the paper argues that in the short run, the positive impact on growth of the identified win-lose policies would not be enough to offset the negative impact they have on inequality and therefore, in the absence of propoor policies that accompany those reforms or additional feedback effects from growth (such as improvements in education or infrastructure), poverty could actually increase. In the long run, however, we find that the growth impact of these policies would offset the negative impact on distribution, and therefore poverty would fall as a result of the implementation of pro-growth policies. These findings would justify the adoption of: (i) a pro-growth policy package at the center of any poverty reduction strategy, and (ii) propoor measures that complement such a package and avoid to the extent possible potential short-run increases in poverty. 


\section{References}

Aitchinson, J. and J. Brown (1966). "The Log-Normal Distribution”, Cambridge, Cambridge University Press.

Alesina, A. and D. Rodrik (1994). "Distributive Policies and Economic Growth". Quarterly Journal of Economics. 109: 465-90.

Arellano, M. and S. Bond (1991). "Some Tests of Specification for Panel Data: Monet Carlo Evidence and an Application to Employment Equations", Review of Economic Studies 58, 277-97

Benabou, R. (1996). "Inequality and Gowth", in B. Bernake and J. Rotemberg fd, NBER Macroeconomics Annual, Cambridge, MIT Press 11-74

Barro, R. (2000). "Inequality and Growth in a Panel of Countries". Journal of Economic Growth, 5, 5-32.

Barro, R. (2002). "Quantity and Quality of Economic Growth", in N. Loayza and R. Soto eds. Economic Growth: Sources, Trends and Cycles. Central Bank of Chile.

Behrman, J., N. Birdsall, and M. Szekely (2001). "Economic Reform and Wage Differentials in Latin America ". Inter American Development Bank, mimeo.

Behrman, J., A. Deolalikar and P. Tinakron (2000). "The Effects of the Thai Economic Crisis and of Thai Labor Market policies on Labor Market Outcomes". Thailand Development Research Institute, Mimeo.

Behrman, J., A. Deolalikar and P. Tinakron (2001). "What Really Happens to Wage Rates During the Financial Crisis?”. University of Pennsylvania, Mimeo.

Bourgignon, F. (2001). "The Growth Elasticity of Poverty Reduction; Explaining Heterogeneity Across Countries and Time Periods", Delta, Mimeo.

Chen, S. and M. Ravallion (2000). "How Did the World's Poorest Fare in the 1990s?"

Policy Research Working Paper \# 2409, The World Bank.

Datt, G. and M. Ravallion (2002). "Why has Economic Growth be More Pro-poor in Some States of India than Others?" Journal of Development Economics, 68, 381-400.

Deninger, K. and L. Squire (1996). “A New Data Set Measuring Income Inequality”. The World Bank Economic Review, 10, 565-591.

Dollar, D and A. Kraay (2002). "Growth is Good for the Poor", Journal of Economic Growth, 7, 195-225

Easterly, W. (1999). "Life during Growth", Journal of Economic Growth, 4, 239-276.

Easterly, W. (2001). "The Middle-Class Consensus and Economic Development", Journal of Economic Growth, 4, 317-335. 
Easterly, W. (2001). "The effect of IMF and World Bank Programs on Poverty", WIDER Discussion Paper \# 2001/102

Easterly, W. and S. Fisher (2001). "Inflation and the Poor", Journal of Money, Credit and Banking , 33, 160-178.

Ferreira, F. (1995). "Roads to equality: Wealth Distribution Dynamics with PublicPrivate Capital Complementarity", LSE Discussion Paper TE/95/286

Ferreira, F. and P. Leite (2003). "Policy Options for Meeting the Millennium Development Goals in Brazil", Policy Research Working Paper \# 2975, The World Bank.

Forbes, K. (2000). "A Reassessment of the Relationship between Inequality and Growth", American Economic Review, 90: 869-97.

Foster, J., J. Greer, and E. Thorbecke (1984). "A Class of Decomposable Poverty Measures", Econometrica, 52, 761-766.

Foster, J. and M. Szekely (2000). "How Good is Growth", Asian Development Review, $18,59-73$

Gallego, F. and N. Loayza (2002), "The Golden Period fro Growth in Chile: Explanations and Forecasts", in Norman Loayza and Raimundo Soto eds. Economic Growth: Sources, Trends and Cycles. Central Bank of Chile.

Galor, O. (2000), "Income Distribution and the Process of Development", European Economic Review, 44, 706-712.

Li H. and H. Zou (1998) "Income Inequality is not Harmful for Growth: Theory and Evidence", Review of Development Economics, 2(3), 318-334.

Li H. and H. Zou (2002) "Infaltion, Growth, and Income Distribution: A Cross-Country Study", Annals of Economics and Finance, 3 85-101.

Loayza, N. P. Fajnzylber and C. Calderon (2002). "Economic Growth in Latin America and the Caribbena: Stylized Facts, Explanations and Forecasts, The World Bank, Mimeo.

Loayza, N. and R. Soto (2002), "The Sources of Economic Growth: An Overview", in Norman Loayza and Raimundo Soto eds. Economic Growth: Sources, Trends and Cycles. Central Bank of Chile.

Lopez, H. and L. Serven (2004), "The mechanics of the poverty-growth-inequality relationship", The World Bank, Mimeo.

Lundberg M., and L. Squire (2003). "The Simultaneous Evolution of Growth and Inequality", The Economic Journal, 113,. 326-344. 
Perotti, R. (1996), "Growth, Income Distribution and Democracy", Journal of Economic Growth, 1, 149-87.

Ravallion, M. (1997). "Can High Inequality Development Countries Escape Absolute Poverty?", Economics Letters, 56, 51-57.

Ravallion, M. (2002). “Inequality Convergence”, The World Bank, Mimeo

Ravallion M. and S. Chen (1997). "What Can New Survey Data Tell us about Recent Changes in Distribution and Poverty?", The World Bank Economic Review, 11, 357-382.

Rodrick, D., A. Subramanian, and F. Trebbi (2002). "Institutions Rule The primacy of Institutions over Geography and Integration in Economic Development". IMF Working Paper \# 02/189

Romer, C. and D. Romer (1998). Does Economic Growth Reduce Poverty?", NBER Working Paper \# 6793.

Sanchez, C. and N. Schady (2003). "Off and Running? Technology, Trade, and the Rising Demand for Skilled Workers in Latin America", Policy Research Working Paper \# 3005, The World Bank.

Son, H. and N. Kakwany and H.(2003). "Poverty reduction: Do Initials Conditions Matter?" Mimeo, The World Bank

Spillimbergo, A. J.L. Londono and M. Szekely (1999). "Income Distribution, Factor Endowments, and Trade Openness", Journal of Development Economics, 59, 77-101. 
Table 1. Theoretical Elasticities under log-normal assumption

\begin{tabular}{|c|c|c|c|c|}
\hline & & Growth & Elasticity & \\
\hline $\mathbf{P L}^{\mathrm{a}} / \mathrm{Gini}$ & 0.3 & 0.4 & 0.5 & 0.6 \\
\hline .16 & -6.2 & -3.3 & -2 & -1.2 \\
\hline .33 & -4 & -2.2 & -1.3 & -0.9 \\
\hline .50 & -2.8 & -1.6 & -1 & -0.7 \\
\hline .66 & -2.1 & -1.2 & -0.8 & -0.5 \\
\hline \multirow[t]{2}{*}{.90} & -1.4 & -0.9 & -0.6 & -0.4 \\
\hline & & Inequality & Elasticity & \\
\hline $\mathbf{P L}^{\mathrm{a}} /$ Gini & 0.3 & 0.4 & 0.5 & 0.6 \\
\hline .16 & 12.9 & 7.7 & 5.3 & 4 \\
\hline .33 & 5.2 & 3.3 & 2.4 & 2 \\
\hline .50 & 2.5 & 1.7 & 1.4 & 1.2 \\
\hline .66 & 1.2 & 0.9 & 0.8 & 0.8 \\
\hline .90 & 0.4 & 0.4 & 0.4 & 0.4 \\
\hline
\end{tabular}

${ }^{\mathrm{a}}$ Poverty line as a share of per capita GDP. Source Lopez and Serven (2004).

Table 2: Descriptive Statistics

\begin{tabular}{lcccc}
\hline Variable & Mean & S.D. & Max & Min \\
\hline $\log ($ Gini $)$ & -.977 & 0.269 & -.296 & -1.79 \\
$\Delta \log ($ Gini $)$ & 0.001 & 0.034 & 0.128 & -0.164 \\
$\log ($ GDP $)$ & 7.931 & 1.043 & 10.61 & 5.38 \\
Growth & 0.016 & 0.038 & 0.276 & -0.229 \\
Education & 3.438 & 1.076 & 5.024 & -.518 \\
Financial depth & -1.465 & 1.015 & 0.734 & -8.205 \\
Trade openness & 0.016 & 0.542 & 2.308 & -1.877 \\
Government burden & -1.928 & 0.432 & -.539 & -4.444 \\
Public Infrastructure & 3.329 & 1.923 & 6.681 & -1.608 \\
Governance & -.002 & 1.706 & 3.468 & -3.256 \\
Price Stability & 4.768 & 0.406 & 8.797 & 4.405 \\
Cyclical Volatility & 0.025 & 0.021 & 0.316 & 0.002 \\
External imbalances & 4.664 & 0.384 & 7.210 & 3.406 \\
Banking crisis & 0.050 & 0.188 & 1.000 & 0.000 \\
External conditions & -0.006 & 0.045 & 0.187 & -0.212 \\
\hline
\end{tabular}


Table 3 Inequality and income levels ${ }^{\mathrm{a}}$

\begin{tabular}{|c|c|c|c|c|c|}
\hline Dependent Variable $\Delta \log ($ Gini $)$ & & Estimation & Method & & \\
\hline & OLS & Fixed Effects & $2 \mathrm{SLS}^{\mathrm{b}}$ & $A \& B^{c}$ & $A \& B^{d}$ \\
\hline Lagged Inequality & -0.0312 & -0.175 & -0.111 & -0.198 & -0.213 \\
\hline Initial Income & $\begin{array}{l}(-4.26) \\
-0.003 \\
(-1.27)\end{array}$ & $\begin{array}{c}(-10.22) \\
-0.007 \\
(-.74)\end{array}$ & $\begin{array}{c}(-2.16) \\
-0.018 \\
(-.69)\end{array}$ & $\begin{array}{c}(-4.18) \\
-0.009 \\
(-.44)\end{array}$ & $\begin{array}{l}(-4.47) \\
-0.021 \\
(-1.02)\end{array}$ \\
\hline \multicolumn{6}{|l|}{ Summary Statistics } \\
\hline $\mathrm{N}$ & 252 & 252 & 172 & 172 & 172 \\
\hline $\mathrm{F}(\mathrm{p}$ val) & 0 & 0 & 0.37 & & \\
\hline Sargan (p val) & & & & 0.4 & 0.68 \\
\hline Second order correlation ( $\mathrm{p}$ val) & & & & 0.27 & 0.16 \\
\hline
\end{tabular}

${ }^{a}$ All regressions include time dummies. t-statistics in parentheses.

${ }^{\mathrm{b}}$ Instruments are: lagged growth and lagged inequality.

${ }^{c}$ Arellano and Bond (1991) GMM estimator, treating initial GDP as an exogenous variable.

${ }^{\mathrm{d}}$ Arellano and Bond (1991) GMM estimator, treating initial GDP as a pre-determined variable.

Table 4. Growth and inequality

\begin{tabular}{|c|c|c|c|c|c|}
\hline Dependent Variable $\Delta \log (Y)$ & & Estimation & Method & & \\
\hline & OLS & Fixed Effects & $2 \mathrm{SLS}^{\mathrm{b}}$ & $A \& B^{c}$ & $A \& B^{d}$ \\
\hline Initial Income & $\begin{array}{l}0.002 \\
(1.09)\end{array}$ & $\begin{array}{l}-0.035 \\
(-5.38)\end{array}$ & $\begin{array}{l}-0.016 \\
(-1.64)\end{array}$ & $\begin{array}{l}-0.075 \\
(-3.09)\end{array}$ & $\begin{array}{l}-0.067 \\
(-3.20)\end{array}$ \\
\hline Inequality & $\begin{array}{r}-0.008 \\
(-1.41) \\
\end{array}$ & $\begin{array}{l}0.011 \\
(1.03)\end{array}$ & $\begin{array}{l}-0.021 \\
(-1.48) \\
\end{array}$ & $\begin{array}{l}-0.008 \\
(-.615) \\
\end{array}$ & $\begin{array}{c}-0.004 \\
(-.18)\end{array}$ \\
\hline \multicolumn{6}{|l|}{ Summary Statistics } \\
\hline $\mathrm{N}$ & 387 & 387 & 117 & 222 & 222 \\
\hline F (p val) & 0.00 & 0.00 & .51 & & \\
\hline Sargan ( $p$ val) & & & & .18 & 0.03 \\
\hline Second order correlation ( $\mathrm{p}$ val) & & & & .69 & 0.25 \\
\hline
\end{tabular}

${ }^{a}$ All regressions include time dummies. t-statistics in parentheses.

${ }^{\mathrm{b}}$ Instruments are: three lagged growth and three lagged inequality observations.

${ }^{c}$ Arellano and Bond (1991) GMM estimator, treating inequality as an exogenous variable.

${ }^{\mathrm{d}}$ Arellano and Bond (1991) GMM estimator, treating inequality as a pre-determined variable.

Table 5. Growth and inequality ${ }^{\mathrm{a}}$

\begin{tabular}{|c|c|c|c|c|c|c|}
\hline Depend. Variable $\Delta \log (\mathrm{Y})$ & Low income ${ }^{b}$ & $\begin{array}{l}\text { Middle } \\
\text { Income }^{b}\end{array}$ & $\begin{array}{c}\text { Sample } \\
\text { High } \\
\text { Income }^{\mathrm{b}}\end{array}$ & $\begin{array}{c}\text { Low } \\
\text { income }\end{array}$ & $\begin{array}{l}\text { Middle } \\
\text { Income }^{\mathrm{c}}\end{array}$ & $\begin{array}{l}\text { High } \\
\text { Income }^{c}\end{array}$ \\
\hline Initial income & $\begin{array}{l}-0.065 \\
(-5.19)\end{array}$ & $\begin{array}{l}-0.040 \\
(-1.60)\end{array}$ & $\begin{array}{l}-0.028 \\
(-2.15)\end{array}$ & $\begin{array}{l}-0.071 \\
(-6.08)\end{array}$ & $\begin{array}{l}-0.015 \\
(-0.81)\end{array}$ & $\begin{array}{l}-0.033 \\
(-2.76)\end{array}$ \\
\hline Inequality & $\begin{array}{l}0.014 \\
(.628)\end{array}$ & $\begin{array}{l}0.031 \\
(1.11) \\
\end{array}$ & $\begin{array}{l}-0.027 \\
(-1.57) \\
\end{array}$ & $\begin{array}{l}0.017 \\
(0.80) \\
\end{array}$ & $\begin{array}{l}0.022 \\
(0.68) \\
\end{array}$ & $\begin{array}{l}-0.006 \\
(-0.27)\end{array}$ \\
\hline \multicolumn{7}{|l|}{ Summary statstics } \\
\hline Number of countries & 14 & 33 & 23 & 14 & 33 & 23 \\
\hline Number of observations & 40 & 101 & 91 & 40 & 101 & 91 \\
\hline Sargan (p val) & 0.25 & 0.06 & 0.98 & 0.76 & 0.23 & 0.67 \\
\hline Second order correl. ( $\mathrm{p}$ val) & 0.58 & 0.77 & 0.76 & 0.58 & 0.66 & 0.94 \\
\hline
\end{tabular}

${ }^{a}$ All regressions include time dummies. t-statistics in parentheses.

${ }^{\mathrm{b}}$ Arellano and Bond (1991) GMM estimator, treating inequality as an exogenous variable.

${ }^{\mathrm{b}}$ Arellano and Bond (1991) GMM estimator, treating inequality as a pre-determined variable. 
Table 6. Determinants of growth and distribution ${ }^{\text {a }}$

\begin{tabular}{|c|c|c|c|c|c|}
\hline & Growth & Growth & $\Delta \log ($ Gini $)$ & $\Delta \log ($ Gini $)$ & $\Delta \log ($ Gini $)$ \\
\hline lagged Inequality & & & -0.242 & -0.224 & -0.227 \\
\hline $\log ($ Gini) & & & $(-13.32)$ & $(-11.98)$ & $(-12.03)$ \\
\hline Inequality & & -0.007 & & & \\
\hline $\log ($ Gini) & & $(1.66)$ & & & \\
\hline Initial GDP per capita & -0.018 & -.125 & & -.031 & .438 \\
\hline$(\log s)$ & $(-3.80)$ & $(-13.44)$ & $(-2.42)$ & $(-2.24)$ & $(6.23)$ \\
\hline Initial GDP per capita squared & & & & & -0.027 \\
\hline (logs -squared) & & & & & $(-6.93)$ \\
\hline Initial output gap & -0.237 & -0.165 & & 0.041 & \\
\hline (log actual/potential GDP) & $(-8.52)$ & $(5.84)$ & & $(0.77)$ & \\
\hline Education & 0.017 & 0.017 & -0.022 & -0.017 & -0.025 \\
\hline (log secondary enrollment) & $(6.70)$ & (3.99) & $(-2.77)$ & $(-1.72)$ & $(-2.50)$ \\
\hline Financial depth & 0.006 & 0.011 & 0.014 & 0.013 & 0.012 \\
\hline (log private domestic credit/GDP) & $(4.28)$ & $(4.04)$ & $(2.83)$ & $(2.91)$ & $(3.30)$ \\
\hline Trade openness & 0.010 & 0.004 & 0.024 & 0.024 & 0.037 \\
\hline (log adjusted trade volume/GDP) & $(3.14)$ & $(0.69)$ & $(3.04)$ & $(2.69)$ & $(4.13)$ \\
\hline Government burden & -0.015 & -0.014 & -0.018 & -0.015 & -0.015 \\
\hline (log government consumption/GDP) & $(-3.18)$ & $(-4.11)$ & $(-2.71)$ & $(-2.17)$ & $(-1.75)$ \\
\hline Public Infrastructure & 0.007 & 0.001 & -0.016 & -0.010 & -0.025 \\
\hline (log per capita telephone lines) & $(2.71)$ & $(0.27)$ & $(-3.32)$ & $(-1.59)$ & $(-4.67)$ \\
\hline Governance & -0.001 & 0.006 & 0.005 & 0.006 & 0.006 \\
\hline (principal component ICRG) & $(-0.68)$ & $(4.63)$ & $(1.74)$ & $(2.02)$ & $(2.21)$ \\
\hline Price Stability & -0.005 & -0.007 & 0.008 & 0.009 & 0.008 \\
\hline$(\log [100+$ inflation rate $])$ & $(-1.89)$ & $(-3.08)$ & $(2.16)$ & $(2.87)$ & $(2.83)$ \\
\hline Cyclical Volatility & -0.277 & -0.242 & 0.112 & 0.228 & 0.258 \\
\hline (std output gap) & $(-3.76)$ & $(-4.30)$ & $(1.41)$ & $(2.22)$ & $(2.48)$ \\
\hline External imbalances & -0.006 & -0.010 & -0.002 & -0.003 & 0.003 \\
\hline (log Dollar index) & $(-3.90)$ & $(-3.36)$ & $(-0.32)$ & $(-0.52)$ & $(0.50)$ \\
\hline Banking crisis & -0.029 & -0.015 & -0.021 & -0.022 & -0.022 \\
\hline (frequency of years) & $(-7.42)$ & $(-4.11)$ & $(-4.02)$ & $(-4.23)$ & $(-5.12)$ \\
\hline External conditions & 0.072 & 0.071 & 0.051 & 0.029 & 0.059 \\
\hline (growth rate of TOT) & $(4.98)$ & $(6.32)$ & $(1.87)$ & $(1.05)$ & $(2.16)$ \\
\hline \multicolumn{6}{|l|}{ Summary statistics } \\
\hline Number of countries & 78 & 48 & 41 & 41 & 41 \\
\hline Number of observations & 350 & 165 & 134 & 133 & 134 \\
\hline Sargan ( $\mathrm{p}$ value) & .99 & .43 & .76 & .78 & .88 \\
\hline Second order correlation ( $\mathrm{p}$ value) & .46 & .21 & .43 & .43 & .40 \\
\hline
\end{tabular}

${ }^{\mathrm{a}}$ The models are estimated with time dummies using Arellano and Bond (1991) two step GMM estimator. t-statistics are in parentheses. All regressions include time dummies. 
Table 7. Net short-run growth elasticiticies of poverty to selected policies ${ }^{b}$

\begin{tabular}{|c|c|c|c|c|c|c|c|c|c|}
\hline \multirow[b]{2}{*}{$\mathbf{P L}^{\mathrm{a}} /$ Gini } & \multicolumn{4}{|c|}{ Education } & \multirow[b]{2}{*}{ PL ${ }^{\mathrm{a}} /$ Gini } & \multicolumn{4}{|c|}{ Finan. Development } \\
\hline & 0.3 & 0.4 & 0.5 & 0.6 & & 0.3 & 0.4 & 0.5 & 0.6 \\
\hline 0.16 & -0.39 & -0.23 & -0.15 & -0.11 & 0.16 & 0.14 & 0.09 & 0.06 & 0.05 \\
\hline 0.33 & -0.18 & -0.11 & -0.07 & -0.06 & 0.33 & 0.05 & 0.03 & 0.03 & 0.02 \\
\hline 0.5 & -0.10 & -0.06 & -0.05 & -0.04 & 0.5 & 0.02 & 0.01 & 0.01 & 0.01 \\
\hline 0.66 & -0.06 & -0.04 & -0.03 & -0.03 & 0.66 & 0.00 & 0.01 & 0.01 & 0.01 \\
\hline \multirow[t]{2}{*}{0.9} & -0.03 & -0.02 & -0.02 & -0.02 & 0.9 & 0.00 & 0.00 & 0.00 & 0.00 \\
\hline & & \multicolumn{3}{|c|}{ Trade Openness } & & & \multicolumn{3}{|c|}{ Government Burden } \\
\hline $\mathbf{P L}^{\mathrm{a}} / \mathrm{Gini}$ & 0.3 & 0.4 & 0.5 & 0.6 & $\mathrm{PL}^{\mathrm{a}} /$ Gini & 0.3 & 0.4 & 0.5 & 0.6 \\
\hline 0.16 & 0.25 & 0.15 & 0.11 & 0.08 & 0.16 & -0.14 & -0.09 & -0.07 & -0.05 \\
\hline 0.33 & 0.08 & 0.06 & 0.04 & 0.04 & 0.33 & -0.03 & -0.03 & -0.02 & -0.02 \\
\hline 0.5 & 0.03 & 0.02 & 0.02 & 0.02 & 0.5 & 0.00 & -0.01 & -0.01 & -0.01 \\
\hline 0.66 & 0.01 & 0.01 & 0.01 & 0.01 & 0.66 & 0.01 & 0.00 & 0.00 & -0.01 \\
\hline \multirow[t]{2}{*}{0.9} & 0.00 & 0.00 & 0.00 & 0.01 & 0.9 & 0.01 & 0.01 & 0.00 & 0.00 \\
\hline & \multicolumn{4}{|c|}{ Infrastructure } & & & \multicolumn{3}{|c|}{ Inflation } \\
\hline $\mathrm{PL}^{\mathrm{a}} /$ Gini & 0.3 & 0.4 & 0.5 & 0.6 & PL $\mathbf{L}^{\mathrm{a}}$ Gini & 0.3 & 0.4 & 0.5 & 0.6 \\
\hline 0.16 & -0.25 & -0.15 & -0.10 & -0.07 & 0.16 & 0.13 & 0.08 & 0.05 & 0.04 \\
\hline 0.33 & -0.11 & -0.07 & -0.05 & -0.04 & 0.33 & 0.06 & 0.04 & 0.03 & 0.02 \\
\hline 0.5 & -0.06 & -0.04 & -0.03 & -0.02 & 0.5 & 0.03 & 0.02 & 0.02 & 0.01 \\
\hline 0.66 & -0.03 & -0.02 & -0.02 & -0.02 & 0.66 & 0.02 & 0.01 & 0.01 & 0.01 \\
\hline 0.9 & -0.02 & -0.01 & -0.01 & -0.01 & 0.9 & 0.01 & 0.01 & 0.01 & 0.01 \\
\hline
\end{tabular}


Table 8. Net long-run growth elasticiticies of poverty to selected policies ${ }^{b}$

\begin{tabular}{|c|c|c|c|c|c|c|c|c|c|}
\hline \multirow[b]{2}{*}{$\mathrm{PL}^{\mathrm{a}} / \mathrm{Gini}$} & \multicolumn{4}{|c|}{ Education } & \multirow[b]{2}{*}{$\mathbf{P L}^{\mathrm{a}} /$ Gini } & \multicolumn{4}{|c|}{ Finan. Development } \\
\hline & 0.3 & 0.4 & 0.5 & 0.6 & & 0.3 & 0.4 & 0.5 & 0.6 \\
\hline 0.16 & -7.03 & -3.82 & -2.37 & -1.50 & 0.16 & -1.32 & -0.65 & -0.36 & -0.17 \\
\hline 0.33 & -4.25 & -2.38 & -1.45 & -1.03 & 0.33 & -1.03 & -0.54 & -0.29 & -0.18 \\
\hline 0.5 & -2.87 & -1.67 & -1.07 & -0.77 & 0.5 & -0.79 & -0.43 & -0.25 & -0.16 \\
\hline 0.66 & -2.09 & -1.22 & -0.83 & -0.54 & 0.66 & -0.63 & -0.35 & -0.22 & -0.12 \\
\hline \multirow[t]{2}{*}{0.9} & -1.36 & -0.89 & -0.60 & -0.41 & 0.9 & -0.44 & -0.28 & -0.18 & -0.11 \\
\hline & & \multicolumn{3}{|c|}{ Trade Openness } & & & \multicolumn{3}{|c|}{ Government Burden } \\
\hline PL $L^{\mathrm{a}} /$ Gini & 0.3 & 0.4 & 0.5 & 0.6 & PL ${ }^{\mathrm{a}} /$ Gini & 0.3 & 0.4 & 0.5 & 0.6 \\
\hline 0.16 & -2.17 & -1.07 & -0.59 & -0.27 & 0.16 & 4.21 & 2.18 & 1.27 & 0.70 \\
\hline 0.33 & -1.71 & -0.89 & -0.48 & -0.30 & $\mathbf{0 . 3 3}$ & 2.95 & 1.59 & 0.90 & 0.60 \\
\hline 0.5 & -1.31 & -0.72 & -0.42 & -0.27 & 0.5 & 2.15 & 1.21 & 0.73 & 0.49 \\
\hline 0.66 & -1.05 & -0.58 & -0.37 & -0.20 & 0.66 & 1.66 & 0.93 & 0.61 & 0.36 \\
\hline \multirow[t]{2}{*}{0.9} & -0.74 & -0.46 & -0.29 & -0.18 & 0.9 & 1.14 & 0.72 & 0.47 & 0.30 \\
\hline & \multicolumn{4}{|c|}{ Infrastructure } & & & \multicolumn{3}{|c|}{ Inflation } \\
\hline PL/Gini & 0.3 & 0.4 & 0.5 & 0.6 & PL ${ }^{\mathrm{a}} /$ Gini & 0.3 & 0.4 & 0.5 & 0.6 \\
\hline 0.16 & -3.26 & -1.79 & -1.13 & -0.73 & 0.16 & 2.15 & 1.17 & 0.73 & 0.47 \\
\hline 0.33 & -1.90 & -1.07 & -0.66 & -0.48 & 0.33 & 1.28 & 0.72 & 0.44 & 0.32 \\
\hline 0.5 & -1.25 & -0.73 & -0.48 & -0.35 & 0.5 & 0.86 & 0.50 & 0.32 & 0.23 \\
\hline 0.66 & -0.90 & -0.53 & -0.36 & -0.25 & 0.66 & 0.62 & 0.36 & 0.25 & 0.17 \\
\hline 0.9 & -0.57 & -0.38 & -0.26 & -0.18 & 0.9 & 0.40 & 0.26 & 0.18 & 0.12 \\
\hline
\end{tabular}


Table 9. Net short-run growth elasticiticies of poverty to selected policies ${ }^{b}$

\begin{tabular}{|c|c|c|c|c|c|c|c|c|c|}
\hline \multirow[b]{2}{*}{ PL $/$ Gini } & \multicolumn{4}{|c|}{ Education } & \multirow[b]{2}{*}{ PL $^{\mathrm{a}} /$ Gini } & \multirow[b]{2}{*}{0.3} & \multicolumn{3}{|c|}{ Finan. Development } \\
\hline & 0.3 & 0.4 & 0.5 & 0.6 & & & 0.4 & 0.5 & 0.6 \\
\hline 0.16 & -0.32 & -0.19 & -0.12 & -0.09 & 0.16 & 0.13 & 0.08 & 0.06 & 0.04 \\
\hline 0.33 & -0.16 & -0.09 & -0.06 & -0.05 & 0.33 & 0.04 & 0.03 & 0.02 & 0.02 \\
\hline 0.5 & -0.09 & -0.06 & -0.04 & -0.03 & 0.5 & 0.02 & 0.01 & 0.01 & 0.01 \\
\hline 0.66 & -0.06 & -0.04 & -0.03 & -0.02 & 0.66 & 0.00 & 0.00 & 0.01 & 0.01 \\
\hline \multirow[t]{2}{*}{0.9} & -0.03 & -0.02 & -0.02 & -0.01 & 0.9 & 0.00 & 0.00 & 0.00 & 0.00 \\
\hline & & \multicolumn{3}{|c|}{ Trade Openness } & & & \multicolumn{3}{|c|}{ Government Burden } \\
\hline PL ${ }^{\mathrm{a}} /$ Gini & 0.3 & 0.4 & 0.5 & 0.6 & $\mathbf{P L}^{\mathrm{a}} /$ Gini & 0.3 & 0.4 & 0.5 & 0.6 \\
\hline 0.16 & 0.25 & 0.15 & 0.11 & 0.08 & 0.16 & -0.10 & -0.07 & -0.05 & -0.04 \\
\hline 0.33 & 0.08 & 0.06 & 0.04 & 0.04 & 0.33 & -0.02 & -0.02 & -0.02 & -0.02 \\
\hline 0.5 & 0.03 & 0.02 & 0.02 & 0.02 & 0.5 & 0.00 & 0.00 & -0.01 & -0.01 \\
\hline 0.66 & 0.01 & 0.01 & 0.01 & 0.01 & 0.66 & 0.01 & 0.00 & 0.00 & 0.00 \\
\hline \multirow[t]{2}{*}{0.9} & 0.00 & 0.00 & 0.00 & 0.01 & 0.9 & 0.02 & 0.01 & 0.00 & 0.00 \\
\hline & \multicolumn{4}{|c|}{ Infrastructure } & & & \multicolumn{3}{|c|}{ Inflation } \\
\hline PL ${ }^{\mathrm{a}} /$ Gini & 0.3 & 0.4 & 0.5 & 0.6 & $\mathbf{P L}^{\mathrm{a}} /$ Gini & 0.3 & 0.4 & 0.5 & 0.6 \\
\hline 0.16 & -0.17 & -0.10 & -0.07 & -0.05 & 0.16 & 0.15 & 0.09 & 0.06 & 0.04 \\
\hline 0.33 & -0.08 & -0.05 & -0.03 & -0.03 & 0.33 & 0.07 & 0.04 & 0.03 & 0.02 \\
\hline 0.5 & -0.04 & -0.03 & -0.02 & -0.02 & 0.5 & 0.04 & 0.02 & 0.02 & 0.01 \\
\hline 0.66 & -0.03 & -0.02 & -0.01 & -0.01 & 0.66 & 0.02 & 0.01 & 0.01 & 0.01 \\
\hline 0.9 & -0.01 & -0.01 & -0.01 & -0.01 & 0.9 & 0.01 & 0.01 & 0.01 & 0.01 \\
\hline
\end{tabular}


Table 10. Net long-run growth elasticiticies of poverty to selected policies ${ }^{b}$

\begin{tabular}{|c|c|c|c|c|c|c|c|c|c|}
\hline \multirow[b]{2}{*}{$\mathrm{PL}^{\mathrm{a}} / \mathrm{Gini}$} & \multicolumn{4}{|c|}{ Education } & \multirow[b]{2}{*}{$\mathbf{P L}^{\mathrm{a}} /$ Gini } & \multicolumn{4}{|c|}{ Finan. Development } \\
\hline & 0.3 & 0.4 & 0.5 & 0.6 & & 0.3 & 0.4 & 0.5 & 0.6 \\
\hline 0.16 & -8.52 & -4.71 & -2.98 & -1.96 & 0.16 & -1.91 & -1.01 & -0.60 & -0.35 \\
\hline 0.33 & -4.85 & -2.76 & -1.72 & -1.26 & 0.33 & -1.27 & -0.69 & -0.40 & -0.28 \\
\hline 0.5 & -3.16 & -1.86 & -1.23 & -0.91 & 0.5 & -0.90 & -0.51 & -0.32 & -0.22 \\
\hline 0.66 & -2.23 & -1.32 & -0.92 & -0.64 & 0.66 & -0.69 & -0.39 & -0.26 & -0.16 \\
\hline \multirow[t]{2}{*}{0.9} & -1.40 & -0.93 & -0.65 & -0.46 & 0.9 & -0.46 & -0.30 & -0.20 & -0.13 \\
\hline & & \multicolumn{3}{|c|}{ Trade Openness } & & & \multicolumn{3}{|c|}{ Government Burden } \\
\hline PL ${ }^{\mathrm{a}} /$ Gini & 0.3 & 0.4 & 0.5 & 0.6 & $\mathbf{P L}^{\mathrm{a}} /$ Gini & 0.3 & 0.4 & 0.5 & 0.6 \\
\hline 0.16 & -3.05 & -1.60 & -0.95 & -0.55 & 0.16 & 5.79 & 3.12 & 1.92 & 1.19 \\
\hline 0.33 & -2.06 & -1.12 & -0.65 & -0.44 & 0.33 & 3.58 & 1.99 & 1.20 & 0.85 \\
\hline 0.5 & -1.48 & -0.84 & -0.51 & -0.35 & 0.5 & 2.45 & 1.42 & 0.90 & 0.64 \\
\hline 0.66 & -1.13 & -0.64 & -0.42 & -0.25 & 0.66 & 1.81 & 1.04 & 0.71 & 0.46 \\
\hline \multirow[t]{2}{*}{0.9} & -0.77 & -0.49 & -0.32 & -0.21 & 0.9 & 1.19 & 0.77 & 0.52 & 0.35 \\
\hline & \multicolumn{4}{|c|}{ Infrastructure } & & & \multicolumn{3}{|c|}{ Inflation } \\
\hline PL/Gini & 0.3 & 0.4 & 0.5 & 0.6 & PL ${ }^{\mathrm{a}} /$ Gini & 0.3 & 0.4 & 0.5 & 0.6 \\
\hline 0.16 & -3.68 & -2.04 & -1.30 & -0.86 & 0.16 & 2.74 & 1.52 & 0.97 & 0.65 \\
\hline 0.33 & -2.07 & -1.18 & -0.74 & -0.55 & 0.33 & 1.52 & 0.87 & 0.55 & 0.41 \\
\hline 0.5 & -1.34 & -0.79 & -0.53 & -0.39 & 0.5 & 0.97 & 0.58 & 0.39 & 0.29 \\
\hline 0.66 & -0.93 & -0.56 & -0.39 & -0.27 & 0.66 & 0.68 & 0.40 & 0.29 & 0.20 \\
\hline 0.9 & -0.58 & -0.39 & -0.27 & -0.19 & 0.9 & 0.42 & 0.28 & 0.20 & 0.14 \\
\hline
\end{tabular}


Figure 1. Potential for poverty dynamics

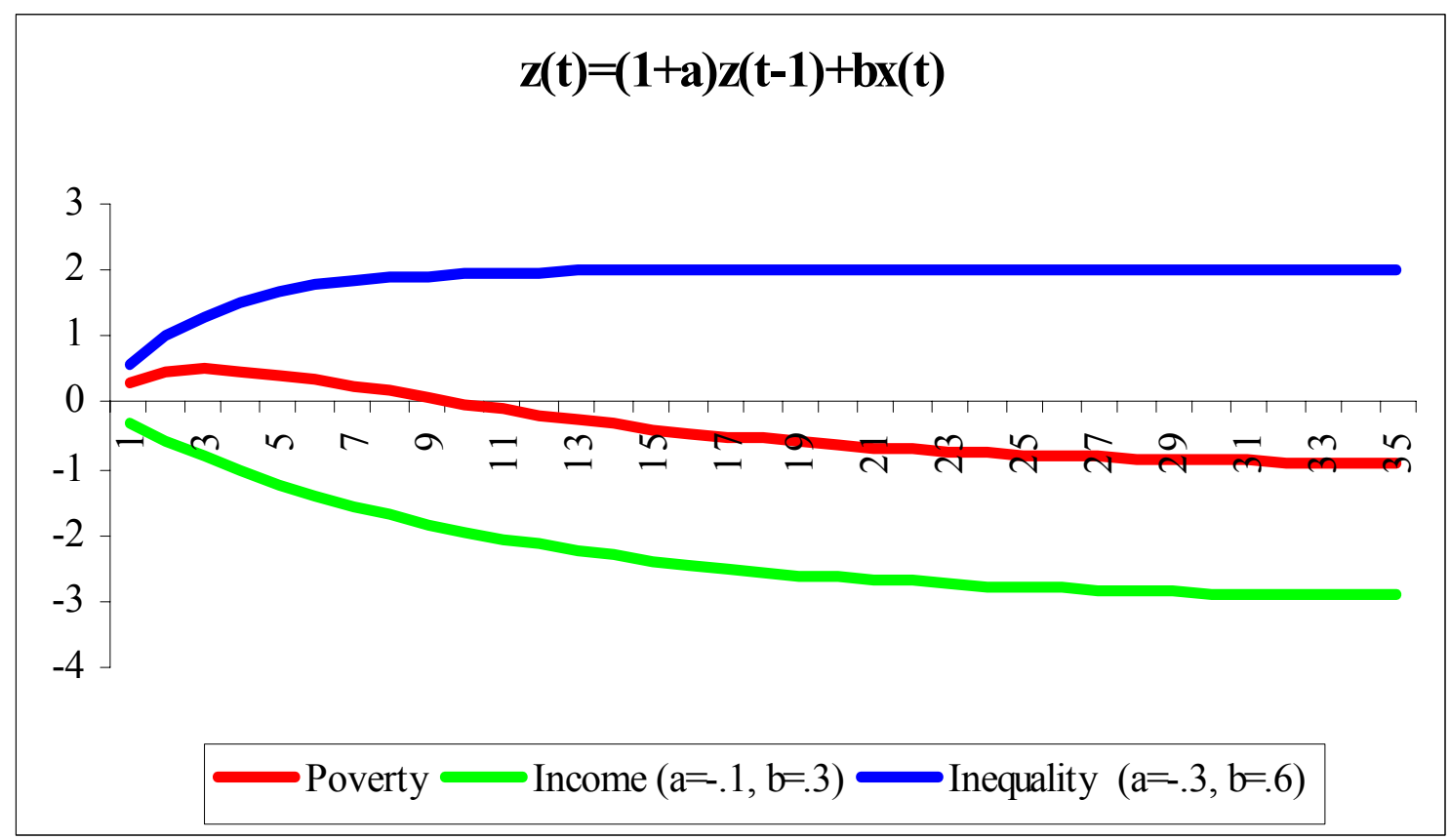

